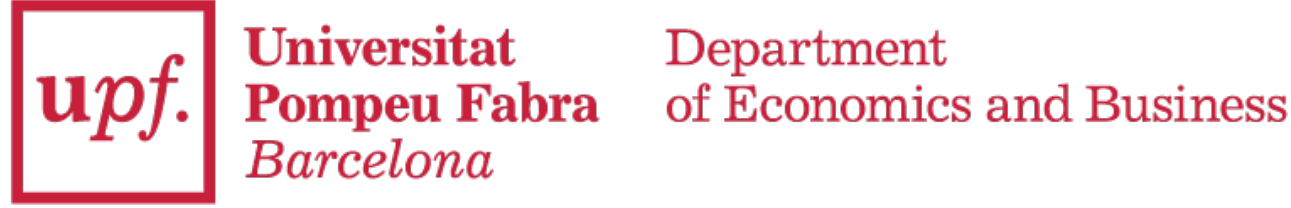

Economics Working Paper Series

Working Paper No. 1681

\title{
The simple economics of white elefants
}

Juan-José Ganuza and Gerard Llobet

November 2019 


\title{
The Simple Economics of White Elephants*
}

\author{
Juan-José Ganuza \\ Universitat Pompeu Fabra and Barcelona GSE \\ Gerard Llobet \\ CEMFI and CEPR
}

November 29, 2019

\begin{abstract}
This paper shows that the concession model discourages firms from acquiring information about the future profitability of a project. Uninformed contractors carry out good and bad projects because they are profitable in expected terms even though it would have been optimal to invest in screening them out according to their value. White elephants are identified as avoidable negative net present-value projects that are nevertheless undertaken. Institutional arrangements that limit the losses that firms can bear exacerbate this distortion. We characterize the optimal concession contract, which fosters the acquisition of information and achieves the first best by conditioning the duration of the concession to the realization of the demand and includes payments for not carrying out some projects.
\end{abstract}

JEL codes: D82, D86, H21, L51.

keywords: Concession contracts, information acquisition, flexible-term concessions.

${ }^{*}$ We would like to thank the editor and two referees for their useful input. We also benefited from comments by Ginés de Rus and audiences at CEMFI, FUNCAS, Universitat de Barcelona, Universitat de les Illes Balears, Universidad de Las Palmas, University of Toronto, XXXI Jornadas de Economía Industrial, 41 Simposio de la Asociación Española de Economía and the Transparency in Procurement conference at the University of Edinburgh. The second author acknowledges the support of the Spanish Ministry of Economics and Competitivity through grant ECO2014-57768 and the Regional Government of Madrid through grant S2015/HUM-3491. Comments should be sent to juanjo.ganuza@upf.edu and llobet@cemfi.es. 


\section{Introduction}

On May 28, 1873 the New York Times published an article called "White Elephants" that starts with the following paragraph

When a Siamese despot takes a grudge against one of his poorer subjects, and determines on his ruin, he does not cut off the delinquent's head and confiscate his property. On the contrary, he makes him a present - he sends him the handsomest and healthiest white elephant he can find. The luckless recipient knows at once that his fate is sealed. He knows that the beast will eat him out of house and home without the possibility, on his part, of resistance. He cannot sell or give away the fatal gift, for no one would accept it, and the attempt to get rid of it even would be direct treason and sacrilege. He sits down with Oriental resignation to submit to the inevitable, and the white elephant devours his substance.

As Bullen (2011) explains, this story is probably a myth as white elephants were considered a symbol of virtue and status in Siam and no king would consider them burdensome. Nevertheless, this story has taken root in the economics literature, popularized in papers such as Robinson and Torvik (2005), and it is now commonly used to identify facilities and infrastructures of little practical use or value. More precisely, white elephants are associated with projects with a negative social return.

The perception that these white elephants are common is widespread and each country has its favorite example: The Montréal-Mirabel International Airport was once the largest in the world in terms of surface: $:^{1}$ the New South China Mall, the largest mall in the world, has sat mostly vacant; the Brisbane's Clem Jones Tunnel had less than $50 \%$ of the

\footnotetext{
${ }^{1}$ Designed for 50 million passengers a year when it opened in 1975 it never handled more than 2.8 million. See Krauss, C. "End of Era Near in Montreal for White-Elephant Airport", Oct 3, 2004.
} 
projected traffic even after tolls were slashed by half; the "Radial" tool highways around Madrid suffered from an even superior demand overestimation $2^{2}$

In this paper we discuss how these white elephants may come about in the construction of public infrastructure by private firms, which are compensated through concession contracts. We argue that standard procurement procedures do not provide incentives for firms to get informed about relevant characteristics of the demand (or the cost) and, as a result, contractors engage in an insufficient screening of projects and end up building unnecessary infrastructures.

Concession contracts, typically signed between a government agency and a private consortium of firms (the concessionaire), involve the transfer of the construction and/or the operation of an asset from the former to the latter for a period of time. Toll highways are a classical example. Their construction is managed by a concessionaire that engages in a long-term contract with a government, designed to recover the large investment cost through user fees (i.e. toll revenues). This kind of schemes has been extended in recent years to all types of Public-Private Partnerships (PPPs) $!^{3}$ They are now common in the construction of roads, prisons, airports, hospitals, railway infrastructure, etc., where the government pays a fee according to their usage. As opposed to what occurs in publicwork contracts where the government assumes all risk and manages the infrastructure directly, concession contracts are used to transfer the risk to the concessionaire.

The risk of such projects is high, since PPP concessions covering infrastructures are long-term contracts - to allow investors to recover the huge upfront investment -, and their profitability depends on variables (traffic, costs, etc.) that are difficult to forecast even over a short horizon. In the case of demand estimation, Bain and Polakovic (2005)

\footnotetext{
${ }^{2}$ According to Engel et al. (2015) first year traffic of the R-2, R-3, R-4 R-5, M-12, and AP-41 highways was between $56 \%$ and $82 \%$ lower than anticipated.

${ }^{3}$ See Engel et al. (2014) for an overview of the rise of the investment in infrastructures financed through PPPs. They report that in Europe they went from irrelevant in 1990 to close to a $€ 30$ billion industry in 2006. In low and middle-income countries PPP invesment reached US\$160 billion in 2010.
} 
report, using a sample of highway concession projects collected by Standard and Poors (S\&P), that first-year traffic volumes average about $76 \%$ of their predicted values and an error with a standard deviation of 0.26. A similar error persisted in the years 2 to 5.4 The underperformance of the concessions is striking since one of its main advantages over a standard public-work contract is precisely the fact that a firm can better assess the demand since its own money is at stake.

Our paper provides an explanation for this result that arises from the interaction between the (asymmetric) consequences of the unpredictability of revenue (or $\operatorname{cost}^{5}$ ) and the incentives for firms to acquire information. Regarding revenue risk, it is often the case that if traffic is lower than expected, concessionaires will force a renegotiation of the contract. Guasch (2004) analyzes concession contracts in Latin America and shows that over $30 \%$ of the concession contracts are renegotiated. In the transportation sector this proportion increases to $54.7 \%$. The results are similar in other contracts characterized by large sunk investments, long concession horizons, and demands risk such as water and sanitation, where renegotiation occurs in $74.4 \%$ of the cases. Importantly, Guasch (2004) also reports that most renegotiations favor the concessionaire by raising tariffs (62\% of the cases) and/or through a decrease in the required investment. In other cases the duration of the concession is extended. These changes are in contrast with what occurs when revenues are higher than expected. In that case concessionaires typically cash the extra profits.

These asymmetries are controversial and, in many countries, they have had an impact in the public debate. In this paper we highlight another important distortion that these asymmetries might entail. The core idea of our work is that if the potential losses of

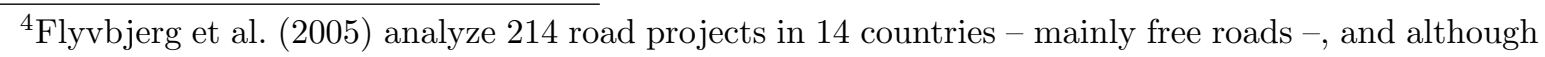
they find almost no overestimation bias, the forecast errors are even larger than in the previous case (a standard deviation of 0.44 ). They also show that railway demand is systematically overestimated worldwide.

5 Flyvbjerg et al. (2003) analyze a sample of 258 infrastructure projects across 20 countries and 5 continents, and find that $90 \%$ of these projects are subject to cost overruns. 
the concessions are limited by a future renegotiation (while the firm appropriates the potential upside) the incentives to acquire information are reduced, negatively affecting project selection.

We propose a principal-agent model where the public sector (the principal) is the sponsor interested in carrying out a public-work project. This project has an unknown value that might be uncovered with the costly acquisition of information by the contractor (the agent). The principal designs a simple concession contract that assigns a proportion of the value of the project to the contractor, for example, through the collection of toll fees during a limited period of time. The agent decides on the acquisition of information and, contingent on that, whether to invest in the project or not. The goal of the principal is to foster the acquisition of information and to induce investment only when the value of the project is higher than its cost.

We characterize the optimal concession contract and we show that typically both objectives (undertaking only projects that generate positive surplus and inducing the acquisition of information when it is efficient to do so) cannot be attained at the same time. As a result some white elephants inevitably emerge in equilibrium. The intuition is as follows. Suppose first that the cost of acquiring information is small. Then, the first best can be attained by designing a concession contract that allocates a share of the revenue to the firm that, once informed, allows it to break even only when a project has a positive social value. Naturally, the incentives to acquire information decrease as its cost increases. To prevent the firm from carrying out the project without information the concession contract must be distorted. In particular, the value of information rises if the share of the revenues that the firm appropriates is reduced and avoiding bad projects becomes more valuable. In this second-best world, some good projects are not undertaken. Furthermore, for a sufficiently high cost of information, the distortions necessary to foster the acquisition of information become too expensive. In that case the principal prefers not 
to induce the acquisition of information, leading to some bad projects (white elephants) to be undertaken in equilibrium. Our result is not specific to the case studied here and similar implications arise when we extend the model to allow for competition.

It is important to notice that our definition of white elephants is restricted to those projects for which proper ex-ante information acquisition was optimal but it did not occur. This is in contrast with the way they are typically interpreted, where evaluation of projects like the ones mentioned earlier is carried out ex-post. The presence of uncertainty inevitably implies that for some projects the costs will never be recovered but this does not imply a bad upfront project selection. The question that our paper addresses is how those bad projects that ex-ante could have been efficiently screened out by investing in information end up being built, and how standard contracts could be adapted to provide the proper incentives and reduce their cost for society.

In practice, as mentioned above, an important element of these concession contracts is the limit on the losses that the contractor can incur due to the renegotiation or the rescue of the infrastructure by the public sector. When we introduce this element in the model, we show that the lower the losses that the firm might absorb, the more critical is the problem of providing incentives for the acquisition of information. As a result, distortions increase when fewer losses can be absorbed leading to more white elephants. An important policy recommendation of our analysis is that governments should compensate bankrupt concessionaries according to the value of the concession and not the incurred cost. This value can be uncovered by auctioning the failed concession ${ }^{6}$

Underlying our analysis there are two important assumptions. First, we assume that the firm can acquire information beyond the knowledge of the principal. This assump-

\footnotetext{
${ }^{6}$ In some countries the limit on the losses takes an explicit legal form. For example, in Spain it is denoted as "Responsabilidad Patrimonial de la Administración", for which an underwater concession is taken over by the state and the firm is compensated according to the cost incurred. In line with the policy recommendation of this paper, a recent change in the Spanish legislation has linked this compensation, instead, to the present value of the cash-flows of the concession at the time of the rescue.
} 
tion is very natural in the case of many PPPs in which the contractor might have an expertise in a particular infrastructure or a particular market. We claim, however, that this assumption is also appealing in a more general context even when the firm does not necessarily possess an advantage in the acquisition of information simply because the public sector typically discloses all the available information prior to the contract. This is due not only to the legal requirements. The provision of information might also entail efficiency gains by inducing a better match between the firm and the project and by reducing the winner's course when the project is allocated through an auction. Thus, our private information acquisition process ought to be understood as the additional precision in the assessment of the value of the project that the firm might obtain by carrying out its own study.

Second, in the benchmark model we take the institution of concessions as given and we do not allow the firm to make any payments above and beyond the cost of construction of the infrastructure plus the cost of acquiring information. As it is well-known, if the firm can make upfront payments the incentive problem in the acquisition of information is alleviated. In the limit, if the firm could pay the expected social value of the project, transferring ownership of the infrastructure, the first best could also be attained regardless of the cost of information acquisition. In the extensions section of the paper we show, however, that in order to keep firm rents under control, it is often optimal to make a limited usage of these upfront payments.7

Our paper is related to the literature that has studied the optimal concession contract. The prevalence of renegotiations highlights the importance of managing the risk of these long-term contracts. While the firm has control of most cost components, the demand is often exogenous to its actions. This might be due to many reasons such as the fact that

\footnotetext{
${ }^{7}$ Arrangements in which the firm buys the concession are rarely observed in practice for several reasons, including among others, legal constraints or financing advantages of the government compared to the firm.
} 
the quality of infrastructures like highways can be specified as part of the contract. As a result, demand risk should be absorbed by the government. Transferring risk to the firm has little effect on performance but might induce contract renegotiation.

One way to achieve this goal is to adjust the duration of the concession to the evolution of the demand. Engel et al. (1997, 2001) proposed the Least Present Value of the Revenues (LPVR) mechanism that has become the most influential way to exploit this idea. The mechanism consists of a flexible-term concession that awards the contract to the bidder that demands the lowest discounted total revenue for the project. The winner is then entitled to receive the revenues of the concession up to the point in which their discounted flow equals the present value of the revenue offered in the bid. At that point the concession expires.

The previous literature has usually ignored the optimal selection of projects, which is the main focus of our work. Here we show that although in our model the revenues of the project are exogenous, a standard application of the LPVR mechanism is suboptimal because it does not provide incentives for firms to acquire information. Taking this effect into account requires some demand risk to be transferred to the contractor in order to provide incentives to get informed 8

However, our main theoretical result, the characterization of the optimal concession contract, relies on a powerful idea of the LPVR mechanism: the need to enrich the concession contract with the information available regarding the realized demand. We show that a concession contract with this feature, together with the possibility of paying for not undertaking a project, can attain the first best. As in the standard application, when the realization of the demand is sufficiently high (indicating that it is likely that information was acquired), the firm is compensated for the total cost. It also receives

\footnotetext{
${ }^{8}$ This is because the expected realization of the demand is different depending on whether the contractor is informed or not. In some sense, the demand is not completely exogenous to the actions taken by the contractor.
} 
a compensation when the project is not carried out. If demand is low, however, the firm is penalized. Although it can be argued that a mechanism involving payments to the firm for not undertaking the project may not be politically feasible, we believe that our approach opens a new way to think about the provision of incentives in concession contracts when project selection matters. We also characterize the second best contract when such a compensation is not feasible and we show that the distortions that arise are similar to those described in the benchmark model.

From a more general point of view our paper is related to the literature that has studied expert delegation in a principal-agent framework. A principal needs the advice of a potentially biased expert for taking a decision and designs a contract for giving the expert incentives to adquire information. This literature started with Lambert (1986) and has continued with contributions like Demski and Sappington (1987) and Feess and Walzl (2004). Zambrano (2019) is probably the closest paper. It studies a setting in which the principal has to choose between a risky project and a safe one, and pays for the expert advice according to the revenues of the project. The optimal contract implies a distortion in project choice in favor of the risky one (since the optimal decision without information is to choose the safe project).

Our paper also fits in the literature on information acquisition, including papers like Persico (2000) and Szalay (2009). In particular, Szalay (2009) analyzes in a principalagent framework how the contract offered by the principal shapes the incentives for the agent to acquire information. As opposed to what we find in our paper, in that framework high-powered contracts, that make the agent's informational rents more risky, increase incentives for information acquisition.

The paper proceeds as follows. Section 2 and 3 discuss the basic model. Section 4 analyzes the effects of limits on the losses that firms can absorb and section 5 characterizes the optimal flexible-term concession contract. Section 6 provides an analysis of several 
extensions of the model. Section 7 concludes. All proofs are relegated to a technical appendix.

\section{The Model}

A government wants to promote a project with a known cost $c>0$. Together with the construction cost the government, also denote as the principal, must account for additional cost $d>0$. This cost might be interpreted as an externality like pollution or as the opportunity cost of the project, such as the benefits of an alternative project that could be funded with the same resources or, in the case of a public work project, the alternative use that resources devoted to it (e.g. land) may have had. The project is not carried out directly by the government but by a private firm, that we denote as the contractor 9

The return of the project is uncertain. It produces a total value $\theta$ drawn from a distribution $G(\theta)$ in the interval $[0,1]$ with density $g(\theta)$, assumed to be positive in all the support.

The value the project can be assessed by the contractor before construction takes place if an amount $k \geq 0$ is invested in a study. We assume that if this cost is incurred the exact value of $\theta$ is revealed 10 Otherwise, the value is only revealed after investment takes place.

Throughout the paper we make the assumption that even without information it is in the interest of society in expected terms that the project is carried out. That is,

$$
E(\theta)=\int_{0}^{1} \theta g(\theta) d \theta>c+d
$$

\footnotetext{
${ }^{9}$ The concession of an infrastructure distinguishes between the firm that builds it, the contractor, and the firm that manages it, the concessionaire. For the purpose of this paper this distinction is irrelevant, and we call the firm simply as the contractor.

${ }^{10} \mathrm{We}$ choose this fully informative signal to provide tractability. As we argue in section 6 similar results arise with a more general informational structure as long as the signal is monotone in the sense of Milgrom (1981). Interestingly, an imperfect signal implies that the average project undertaken is worse.
} 
Thus, the main effect of acquiring information is to reduce the proportion of projects that are undertaken by weeding out those that are known to have a low value. It is natural to assume that projects have an ex-ante positive social value since we are in a contractual stage. Beyond this assumption our results are distribution free.

In exchange for incurring in a construction cost $c$, the principal awards the contractor a compensation consisting of a proportion $\beta \in[0,1]$ of the returns from the project. This is typically the case, for example, in infrastructures like toll highways. In that case, we can interpret $\theta$ as the total traffic generated and $\beta$ as how many years the contractor will be able to collect tolls from it 11 In section 6 we extend the model to consider the possibility that the firm can also make upfront payments.

Furthermore, we also assume that the investment in obtaining information can only be carried out by the contractor. An interpretation of this assumption is that the government has already collected information which has been made public and it is already embedded in the distribution $G(\theta)$. The firm can invest in obtaining a more accurate signal. Importantly, we assume that whether the firm has incurred in the cost of information $k$ or not is not contractible.

The government's objective function is to maximize social welfare. As we will see next, attaining this aim implies minimizing decision errors: reducing the possibility that projects with a low value $\theta$ are carried out while, at the same time, not passing over socially profitable investment possibilities. When several contracts lead to the same level of social welfare we will assume that the government chooses the one that minimizes firm profits 12

\footnotetext{
${ }^{11}$ In this paper we abstract from other important dimensions, like the amount of the toll, which affects how much of the cost is recovered each period, and can be compensated with the duration of the concession. This is not a new trade-off and it has been studied in other context like in the case of patents, starting with classical works like Nordhaus (1969). Weyl and Tirole (2012) study how prices can also be used in order to screen private information in such a context.

${ }^{12}$ This tie-breaking allocation rule naturally arises when the government faces a cost of public funds which, for simplicity, we do not consider in this paper.
} 
Before we characterize the optimal contract we briefly discuss the first best. This allocation will become useful as a benchmark for the rest of the paper.

\subsection{The First Best}

The assumption in equation (1) implies that if no information is acquired the expected value of a project of unknown return $\theta$ is higher than $c+d$ and it should always be carried out. Thus, information should be acquired if it produces higher social welfare. The investment of an amount $k$ uncovers the return of the project and it allows the selection of only those for which $\theta \geq \underline{\theta}$. Acquiring information will be efficient if

$$
\max _{\underline{\theta}} \int_{\underline{\theta}}^{1}[\theta-(c+d)] g(\theta) d \theta-k \geq \int_{0}^{1} \theta g(\theta) d \theta-(c+d),
$$

leading to an optimal threshold in the value of the project of $\underline{\theta}^{s}=c+d$. Hence, information should be acquired if

$$
k \leq K^{s} \equiv-\int_{0}^{\underline{\theta}^{s}}[\theta-(c+d)] g(\theta) d \theta
$$

In other words, if $k \leq K^{s}$ information is gathered and all bad projects are screened out. Instead, if $k>K^{s}$, it is socially optimal not to acquire information and all projects will be carried out.

\section{The Optimal Contract}

In order to illustrate our analysis it is useful to start by pointing out that if information could be acquired by the contractor at no cost the first best could be easily implemented. We know that this firm would always acquire information and it would only carry out those projects that produced a positive return, identified as $\beta \theta \geq c$. As a result, the first best in terms of project selection can only be attained by choosing $\beta^{*}=\frac{c}{c+d}<1$. The intuition is straightforward. Since the firm does not internalize the opportunity cost of the investment, $d$, the duration of the concession must be reduced in order to eliminate the excessive incentives to invest. 
When $k>0$ the contractor's decision to get informed will depend on whether the losses avoided by using this information are greater or lower than $k$. That is, the contractor will get informed if

$$
\max _{\underline{\theta}} \int_{\underline{\theta}}^{1}[\beta \theta-c] g(\theta) d \theta-k \geq \int_{0}^{1} \beta \theta g(\theta) d \theta-c .
$$

This problem yields a profit-maximizing threshold $\underline{\theta}^{*}=\frac{c}{\beta}$ under which the contractor will decide to get informed if

$$
k \leq K(\beta) \equiv-\int_{0}^{\frac{c}{\beta}}[\beta \theta-c] g(\theta) d \theta
$$

Notice that the critical value $K(\beta)$ is decreasing in $\beta$,

$$
K^{\prime}(\beta)=-\int_{0}^{\frac{c}{\beta}} \theta g(\theta) d \theta<0 .
$$

The intuition for this negative relationship can be easily explained using Figure 1, which computes the returns for different values of $\theta$. The dashed line corresponds to the social welfare generated. The dotted line computes private profits under a concession $\beta^{*}=\frac{c}{c+d}$. As discussed before, by construction, profits of an informed firm are positive in this case if and only if $\theta \geq \underline{\theta}^{s}$. Notice, however, that the value of information for the firm is lower than the value for society, since the gains from avoiding bad projects - low $\theta-$ are smaller 13 As a result, when $k>K\left(\frac{c}{c+d}\right)$ a conflict arises. Providing incentives to invest in such a case requires lowering the profits when a bad project is undertaken, which implies $\beta<\frac{c}{c+d}$ as shown in the solid line of the figure. However, this decrease in profits discourages the contractor, once informed, to carry out some profitable projects with $\theta \in\left[\underline{\theta}^{s}, \underline{\theta}^{*}\right)$. The next lemma summarizes this discussion.

Lemma 1. For values of $k \in\left(K\left(\frac{c}{c+d}\right), K^{s}\right)$ the first best cannot be attained.

\footnotetext{
${ }^{13}$ The profits from undertaking projects with $\theta \geq \underline{\theta}^{s}$ are also smaller than the social welfare they generate. However, this difference does not affect the value of information since for those projects the profits with and without information are the same.
} 


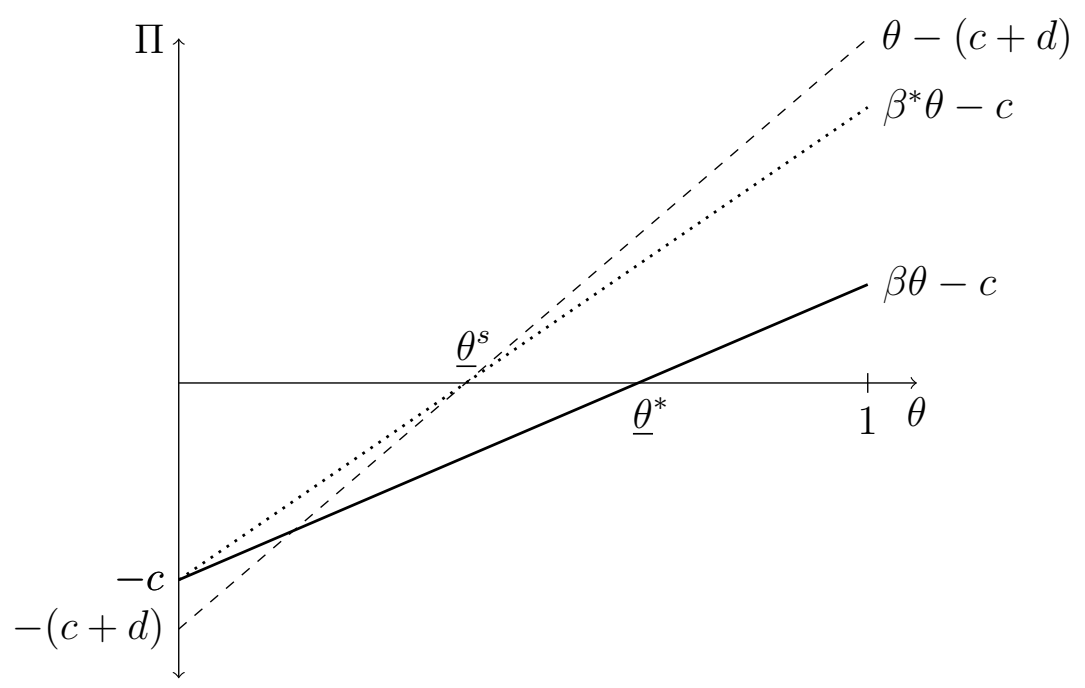

Figure 1: Losses and profits depending on $\theta$.

This result implies that the first best allocation will be possible in two circumstances. First, when $k$ is small the firm has incentives to get informed and, thus, $\beta^{*}$ maximizes social welfare. Second, when $k$ is sufficiently high so that gathering information is not socially optimal there is no incentive problem and it is enough that $\beta$ allows the firm to break even in expected terms when all projects are undertaken.

In the remaining situations, when the first best cannot be attained, the government trades off two types of distortions. On the one hand, it can give up on providing incentives for the firm to learn and, thus, bad projects will be carried out. On the other, it can distort $\beta$ in order to provide incentives for the contractor to learn but, as a result, forestall some good projects.

These two distortions will give raise to standard Type-I and Type-II errors. Type-I errors arise because in order to entice the contractor to invest, the value of $\beta$ must be distorted downwards. The lower the $\beta$ the higher is $K(\beta)$. That is, the incentives to get informed increase since the losses the contractor suffers when $\theta$ is low and the project has been carried out due to the lack of information are higher. Of course, this distortion implies that a range of projects with a value of $\theta$ higher than $c+d$ will not be undertaken since $\beta$ is too low. Thus, the optimal $\beta$ is the highest value that provides incentives for 
the contractor to get informed, $\tilde{\beta}(k)=K^{-1}(k)$. The cost of these Type-I errors for a given $k$ is

$$
E_{I}(k)=\int_{c+d}^{\frac{c}{\bar{\beta}(k)}}(\theta-(c+d)) g(\theta) d \theta .
$$

Following the previous discussion, Type-I errors arise because projects with $\theta \in\left[c+d, \frac{c}{\tilde{\beta}(k)}\right)$ generate a positive social value greater but will not be carried out if the firm gets informed. Of course, the size of this error is increasing in $k$, since the higher is this cost the higher will need to be the distortion in $\beta$ to entice learning.

Type-II errors arise in those cases in which the principal decides not to provide incentives to invest in learning the value of the project. Consequently all projects are carried out implying a social cost of

$$
E_{I I}=-\int_{0}^{c+d}(\theta-(c+d)) g(\theta) d \theta=K^{s}
$$

that must be compared with the savings that society accrues when $k$ is not incurred. The optimal contract is characterized next by comparing Type-I and Type-II error costs.

Proposition 1. The optimal contract corresponds to

$$
\beta^{*}(k)= \begin{cases}\frac{c}{c+d} & \text { if } k \leq K\left(\frac{c}{c+d}\right), \\ \tilde{\beta}(k) & \text { if } K\left(\frac{c}{c+d}\right)<k<\tilde{K} \\ \frac{c}{E(\theta)} & \text { otherwise, }\end{cases}
$$

where

$$
E_{I}(\tilde{K})+\tilde{K}=E_{I I}
$$

Since $E_{I I}=K^{s}, \tilde{K}<K^{s}$ and White Elephants arise when $k \in\left[\tilde{K}, K^{s}\right)$.

Figure 2 illustrates how the optimal value of $\beta$ changes when $k$ varies together with the lowest value of the project that will be implemented, $\underline{\theta}^{*}$. As Lemma 1 showed, the optimal contract corresponds to the first best when $k$ is very low or very high, $k \leq K\left(\frac{c}{c+d}\right)$ or $k \geq K^{s}$. For intermediate values of $k$ the principal has to choose between the Type-I error plus the cost of learning and the Type-II error. This comparison leads to two regions. 

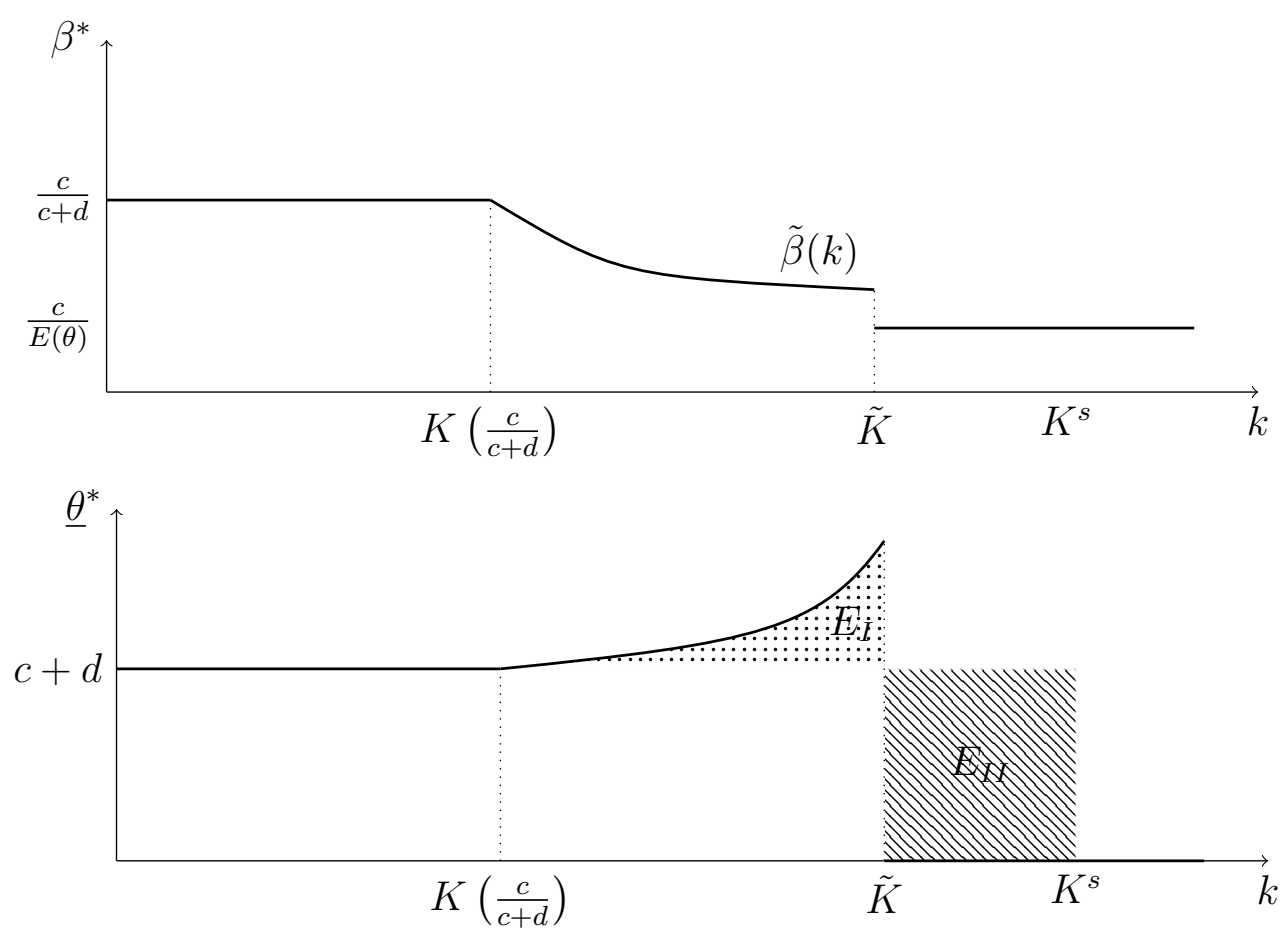

Figure 2: Second best as a function of $k$.

Note: The upper figure depicts the optimal share of the project that the contractor should keep. The lower figure identifies the value of the projects that are carried out. Those that have a value higher than $c+d$ that are not carried out result in Type-I errors. Those that have a value lower than $c+d$ and are not carried out in spite of $k<K^{s}$ result in Type-II errors (a.k.a white elephants).

When $K\left(\frac{c}{c+d}\right)<k<\tilde{K}$ the contractor will invest because the lower Type-I error - the dotted area in Figure 1 - dominates. Instead, when $k \in\left[\tilde{K}, K^{s}\right)$ it is not optimal to provide incentives for the contractor to get informed. The Type-II error becomes less costly. The low value projects that are carried out in this region (when $\theta<c+d$ ) will be identified as white elephants, because the firm does not find worthwhile to acquire information although it is socially optimal to do so. These projects that should have been screened out are identified as the dashed area in Figure 2.

\section{Limited Losses}

In the basic model the contractor invests in the project an amount $c+k$ or $c$ depending on whether information has been acquired or not. This investment sets a cap on the 
maximum losses that the firm might bear due to limited liability. In many cases, however, the government imposes additional limits on those losses. In countries like Spain the construction of public projects has traditionally included an amount that the government will cover in case some unexpected costs arise or if the demand turns out to be lower than anticipated. More generally, when such an explicit commitment does not exist, the prospects of a costly and uncertain renegotiation process might motivate governments to subsidize underwater concessions to keep them under operation. We denote the maximum losses that the firm may incur as $L$ and we restrict them to be between 0 and $c$.

The analysis in this case is very similar to the one we conducted in section 3 . Because now the losses are capped by $L$, profits will be $-L$ for any realization $\theta<\frac{c-L}{\beta}$. As a result we obtain that information is acquired if

$$
\max _{\underline{\theta}} \int_{\underline{\theta}}^{1}[\beta \theta-c] g(\theta) d \theta-k \geq \int_{\frac{c-L}{\beta}}^{1}[\beta \theta-c] g(\theta) d \theta-L G\left(\frac{c-L}{\beta}\right) .
$$

Notice that when the firm gets informed, losses will never be incurred and, as a result, $L$ does not play a role. The previous expression yields a new threshold on the cost of information that provides incentives for the contractor to get informed and that, with some abuse of notation, we denote as $K(\beta, L)$. When $L=c$ we obtain the same threshold as in the baseline model, $K(\beta)$. At the other extreme, when $L=0$, the threshold is equal to 0 . In this last case, the contractor will never get informed because the value of information is precisely to eliminate those realizations of $\theta$ for which the firm makes losses and this is something that $L=0$ already guarantees at no cost for the contractor.

The optimal contract can again be cast in terms of the comparison between Type-I and Type-II errors.

Proposition 2. The optimal contract under limited losses corresponds to

$$
\beta^{*}(k, L)= \begin{cases}\frac{c}{c+d} & \text { if } k \leq K\left(\frac{c}{c+d}, L\right), \\ \tilde{\beta}(k, L) & \text { if } K\left(\frac{c}{c+d}, L\right)<k<\tilde{K}(L), \\ \frac{c}{E(\theta)} & \text { otherwise }\end{cases}
$$


where

$$
E_{I}(\tilde{K}, L)+\tilde{K}=E_{I I}
$$

The structure of the optimal contract bears many similarities with the one in the benchmark case. When $k$ is low the first best can be implemented but, compared to the benchmark case, the threshold value is lower, since $K\left(\frac{c}{c+d}, L\right)$ increases with $L$. For intermediate values of $k$, the principal prefers to induce learning by distorting $\beta$ downwards. As in the benchmark case, for a given $k$, it is optimal to choose the highest value of $\beta$ that guarantees that learning takes place, $\tilde{\beta}(K, L)$. In other words, $k=$ $K(\tilde{\beta}, L)$. Because the only distortion is that some good projects are not carried out, only Type-I errors can arise and their cost can be computed as

$$
E_{I}(k, L)=\int_{c+d}^{\frac{c}{\tilde{\beta}(k, L)}}(\theta-(c+d)) g(\theta) d \theta
$$

which is decreasing in $L$.

For higher values of $k$ it is not optimal for the principal to induce learning at all and, thus, only Type-II errors can arise. These errors are identical to the ones in the benchmark case and, in particular, they do not depend on $L$ which, from a social point of view, is just a reallocation of surplus towards the firm.

The minimum value of $k$ for which it is not optimal to induce learning corresponds to the one for which the cost of the Type-I error plus the cost of learning equates the cost of the Type-II error, as indicated in (4). Notice, though, that since $E_{I}$ is decreasing in $L$ we have that the critical value $\tilde{K}$ is increasing in $L$. That is, when the contractor can absorb fewer losses the social value of fostering information acquisition is reduced and the threshold value for which it is optimal that the firm carries out all projects decreases. This effect implies that the white elephants are more likely when $L$ is lower. Figure 3 also shows that $\beta^{*}$ is decreasing in $L$.

All this discussion can be summarized in the following result. 

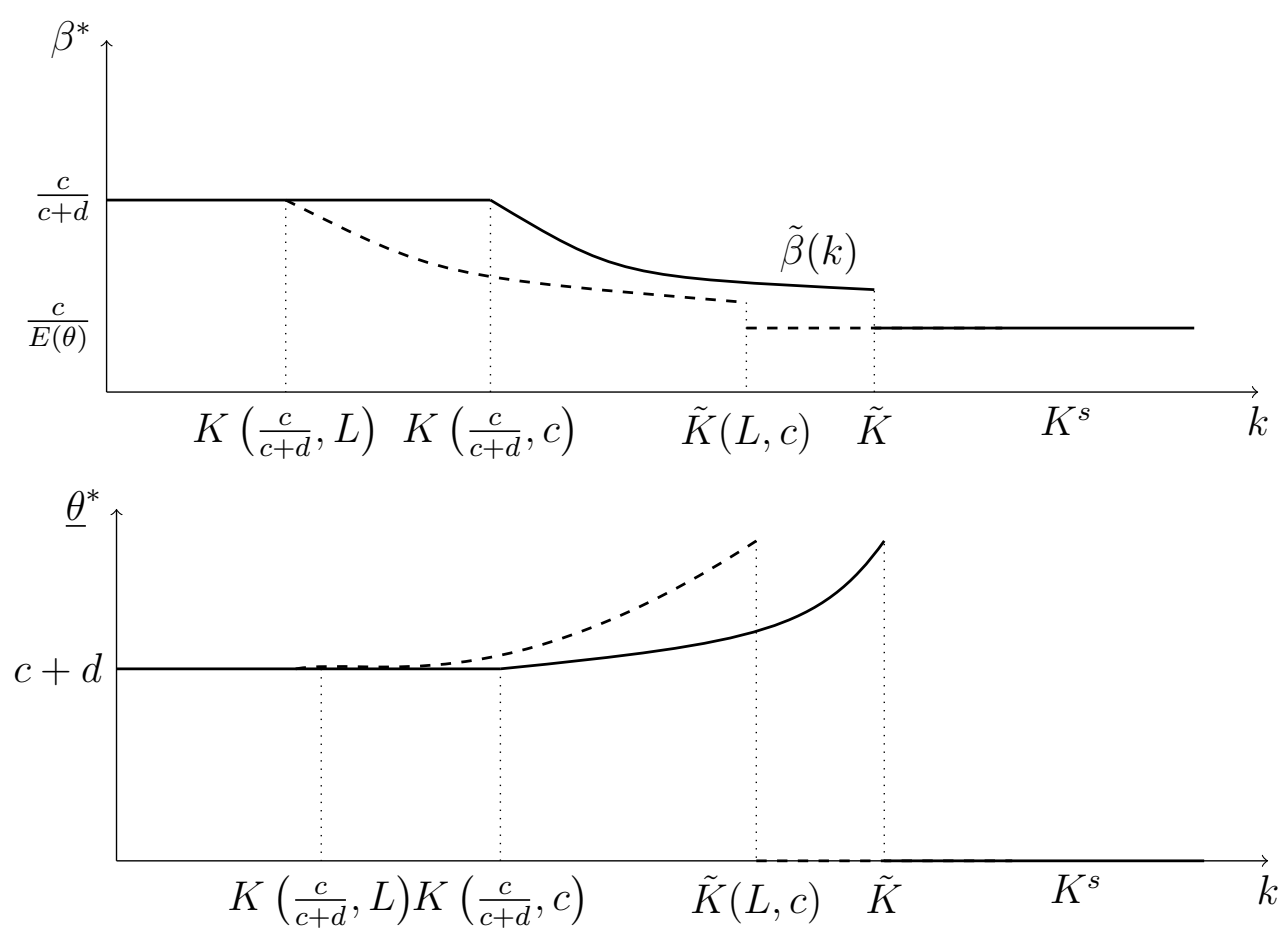

Figure 3: The effect of the limit in losses. The dashed line corresponds to $L<c$ whereas the solid line indicates the benchmark case $L=c$.

Corollary 1. When L increases,

1. Social welfare increases,

2. White elephants are less likely, and

\section{Equilibrium decision errors are smaller.}

As it transpires from the previous analysis, institutional reforms aiming to increase $L$ will raise social surplus. This occurs, for example, in the case of renegotiation of an underwater concession (a situation in which future revenues are expected not to be enough to repay the remaining debt). Our results indicate that if the contractor expects to receive more than the present value of the future cash-flows of the concession, the ex-ante incentives to acquire information will be harmed. A commitment to prevent that renegotiation could be acquired if the government specified that in case of bankruptcy the concession would be taken over and auctioned off again. The receipts from this auction 
would be used to compensate the previous concessionaire.

From the previous discussion we can also conclude that enlarging the space of contracts that can be offered to the contractor by including a subsidy $T \geq 0$ to be paid to the firm will have a similar effect as limited liability. Consider two contracts $(T, \beta)$ that generate the same selection of project. The one with the highest subsidy implies a lower $\beta$. This contract generates lower expected costs when no information is acquired and, consequently, a lower incentives to acquire information 14

Remark 1. Suppose that the principal offers a concession with duration $\beta$ together with a subsidy $T \geq 0$. Among all the contract combinations that lead to a threshold $\underline{\theta}$ above which the projects are carried out, the incentives to acquire information are maximized when $T=0$.

As we will see next, however, the previous result may change when the subsidy might be a function of $\theta$. In that case, a higher subsidy can be associated to a higher realization of $\theta$ and, as a result, be used to provide incentives and compensate the costs of information acquisition.

\section{Flexible-Term Concession Contracts}

The optimal contract characterized in the previous sections assumed that $k$ was not contractible but that the contract offered, following standard practice in concessions, could not be a function of $\theta$. In recent years, however, it has been pointed out that the distortions associated with the threat of renegotiation would be mitigated if the contract could depend on the realized return of the project. Engel et al. (2001) have convincingly

\footnotetext{
${ }^{14}$ More specifically, all contracts that lead to the same marginal project $\underline{\theta}$ imply $T(\beta, \underline{\theta})=c-\beta \underline{\theta}$. In those contracts the firm acquires information if

$$
k \leq K(\beta, \underline{\theta})=-\int_{0}^{\underline{\theta}}[\beta \theta-c+T(\beta, \underline{\theta})] g(\theta) d \theta=\int_{0}^{\underline{\theta}} \beta(\underline{\theta}-\theta) g(\theta) d \theta .
$$

This threshold value is increasing in $\beta$.
} 
argued that in infrastructures such as highways the duration of the concession should depend on the realized traffic. Highways that are busier than expected should be subject to a lower concession period, enough for the contractor to recover the investment costs. Those that are less successful than expected should see the duration of the concession extended as much as necessary until the firm breaks even.

In our benchmark model this kind of contracts can be easily accommodated by assuming that $\beta(\theta)$. In particular, if $k=0$ the Least Present Value of Revenues mechanism implements the first best by setting $\beta(\theta) \theta-c=0$. This mechanism removes all risk from the firm and guarantees that it obtains zero profits regardless of the realization of the demand. However, when $k>0$ this standard flexible-term contract is inefficient in terms of providing incentives for firms to get informed. By shifting the risk from the firm to the government, the mechanism also decreases the incentives for the firm to become informed in the first place. In some sense, it operates as a demand-contingent loss limit and, thus, it suffers from problems similar to those discussed in previous sections.

This flexible-term contract, however, can be improved upon if rents are provided to compensate the cost of learning and these rents are doled out when the firm only undertakes high value projects. The next proposition shows that a flexible-term contract achieves the first best if it also introduces a payment for the firm not undertaking some projects.

Proposition 3. A Flexible-Term Contract with payments when the project is not carried out can implement the first best for any value of $k$. This contract can be characterized as:

- If $k \leq K^{s}$ and

- the firm does not invest, it receives a payment $\rho_{N}(k)$,

- the firm invests when

$* \theta \geq c+d$, then $\beta^{*}(\theta)=\frac{c+\rho_{P}(k)}{\theta}$, 


$$
* \theta<c+d, \text { then } \beta^{*}(\theta)=0 \text {. }
$$

where

$$
\begin{aligned}
& \rho_{N}(k)=\max \left\{\frac{k}{G(c+d)}-c, 0\right\}, \\
& \rho_{P}(k)=\rho_{N}(k)+\frac{k}{1-G(c+d)} .
\end{aligned}
$$

- If $k>K^{s}$ then $\beta^{*}=\frac{c}{E(\theta)}$.

When $k \leq K^{s}$ the previous contract consists of three different elements. In the spirit of other flexible-term contracts, $\beta^{*}(\theta)$ is such that when the project is socially valuable the firm obtains the same compensation regardless of $\theta$. This compensation is higher than the cost $c$ and equal to $\rho_{P}(k) \geq k$ which, in expected terms, covers the cost of information. When the project undertaken has a low value, however, the firm is awarded a concession with $\beta=0$ as this is an indication that no information was acquired.

Rewarding the firm when $\theta$ is high might undermine the incentives to acquire information in the first place as it might anticipate in some cases positive profits from not paying $k$ and undertaking the project anyway. For some parameter values the punishment that $\beta=0$ implies when $\theta$ is small might make this an irrelevant concern. When this punishment is not enough to provide incentives to acquire information, increasing $\beta(\theta)$ when the $\theta \geq \underline{\theta}^{s}$ does not help since this payment is always received. Thus, we need to introduce a third element in the contract which is a compensation $\rho_{N}(k)$, when the contractor decides not to carry out the project. This payment works because it increases the wedge in profits between undertaking low value projects and not doing so and, as a result, it provides additional incentives to become informed ${ }^{15}$

\footnotetext{
${ }^{15}$ In practice extreme punishments are unlikely to be implementable. For example, the government may learn about the realization of $\theta$ when the firm has already operated the project for some time and, therefore, this punishment might imply that the revenues can be reclaimed at no legal cost. When $\beta$ has a lower limit the previous proposition suggests that $\rho_{N}(k)$ should increase.
} 
Notice, though, that when the contractor is paid for not carrying out the project it will obtain positive rents. The reason is that in this case the firm could guarantee a profit of $\rho_{N}(k)$ by not acquiring information and never carrying out the project. Thus, the optimal contract must provide higher profits when the firm is informed and this is the reason why $\rho_{P}(k)$ is increasing in $k$ and $\rho_{P}(k)>\rho_{N}(k)$. This last inequality also explains why subsidies are useful in this case, as opposed to what we concluded for the contracts studied in the benchmark model. In Remark 1 pointed out that subsidies were not optimal since they could not be associated to specific realizations of $\theta$. Here $\rho_{P}(k)$ is only paid when $\theta \geq c+d$, making transfers weakly increasing in $\theta$.

Finally, notice that when the firm carries out the project we are interpreting the payment $\rho_{P}(k)$ as an increase in $\beta(\theta)$, and we implicitly allow for $\beta^{*}(\theta)>1$. This is without loss of generality since it is immediate that because we can condition on $\theta$, any combination of a proportion of the project and subsidy that leads to the same revenue $\beta \theta+T$ provides identical incentives.

Of course, a contract like the previous one might not be feasible in some contexts. For example, suppose that the capacity of a firm to carry out a project is unknown to the principal. A contract like the one described here might attract firms that are not qualified just because they expect to receive a positive payment $\rho_{N}(k)$ from not carrying out the project, without the need to invest in information. Similarly, a problem would also arise if the firm were the one proposing the project as it could come up with phony concessions, contracts that should never be undertaken, just to be compensated for that. Finally, another reason why such a contract might not be realistic is the fact that when the firm gets large rents this contract might entail a high social cost either for political reasons (because the firm is paid when the project is not carried out) or due to the distortionary taxation involved.

If the previous payments are not possible, depending on parameter values the gov- 
ernment may still induce learning under a Flexible-Term concession for all $k \leq K^{s}$. In particular, notice that for any $\theta \geq c+d$ the contractor obtains an increase in profits of $k$ when it is not informed. When $\theta<c+d$, however, it is still optimal for the government to impose the maximum penalty on the contractor which means that $\beta(\theta)=0$. Comparing expected profits we obtain that the firm prefers to get informed if

$$
k \leq c G(c+d)
$$

Therefore, the first best will still be possible if $K^{s} \leq c G(c+d)$ which is consistent with the result in the previous proposition that the first best was implementable with $\rho_{N}(k)=0$. Otherwise, similar inefficiencies to those discussed in the benchmark case will arise for $k \in\left(c G(c+d), K^{s}\right]$. The next proposition characterizes the contract that implements the second best.

Proposition 4. The optimal Flexible-Term Contract when payments for not carrying out the project are not possible can be characterized as:

- If $k \leq K^{f t}$ and

$-\theta \geq \underline{\theta}^{f t}$ then $\beta^{*}(\theta)=\frac{c+\rho_{P}(k)}{\theta}$

$-\theta<\underline{\theta}^{f t}$ then $\beta^{*}(\theta)=0$,

where $\underline{\theta}^{f t}=\max \left[c+d, G^{-1}\left(\frac{k}{c}\right)\right]$ and $\rho_{P}(k)=\frac{k}{1-G\left(\underline{\theta}^{f t}\right)}$.

- If $k>K^{f t}$ then $\beta^{*}=\frac{c}{E(\theta)}$.

The threshold value $K^{f t}$ is defined as

$$
K^{f t}=-\int_{0}^{\underline{\theta}^{f t}}[\theta-(c+d)] g(\theta) d \theta \leq K^{s}
$$

Notice that the contract we describe here is not unique and other combinations of $\beta(\theta)$ may lead to the same outcome. When the probability that the low realizations of $\theta$ 
arise and condition (5) is unlikely to hold, distortions similar to those in the benchmark problem will arise. Some projects, those with $\theta \in\left[\underline{\theta}^{s}, \underline{\theta}^{f t}\right)$, will not be implemented in order to penalize the firm when no information is gathered. For this reason, the value of information will be lower in this case. As a result, for intermediate values of the cost of information, $k \in\left(K^{f t}, K^{s}\right]$, the firm will carry out the project uninformed, leading to white elephants.

Notice also that an important consequence of eliminating negative payments is that the firm will obtain a higher reward when $\theta$ is high, compared to the first best. The cost of information must be reimbursed through fewer states of the world.

\section{Extensions of the Results}

In this section we extend the discussion of the model in several directions. We analyze the implications of more general information structures, the effects of allowing the firm to make upfront payments and consider the dead-weight loss associated with the market power necessary for the firm to recoup the investment during the concession period. We also study the case in which ex-ante, without information, it is not worthwhile to undertake the project. Finally, we show that competition generates similar distortions to the ones analyzed in the one firm case.

\subsection{Imperfect Information over $\theta$}

In the benchmark model we have assumed that the signal was fully informative for tractability reasons. We now consider the case in which the firm, after paying the cost $k$, learns the value of the project with error.

In particular, we consider an information structure, $\Phi(\sigma \mid \theta)$ with density $\phi(\sigma \mid \theta)$ where

$\sigma \in[0,1]$ is a signal of $\theta$ distributed according to $\Phi(\sigma)$ which satisfies the following 
condition property,

$$
\Phi(\theta)=\int_{0}^{1} \Phi(\sigma \mid \theta) d g(\theta)
$$

We assume $\phi(\sigma \mid \theta)$ is log-concave so that the signal structure $\Phi(\sigma \mid \theta)$ is monotone. This condition implies that higher signal realizations lead to a higher conditional distribution of $\theta$ in the first-order stochastic sense.

The model with imperfect information implies that once the firm has paid the cost $k$, it obtains a signal regarding the value of the project. Because the signal is monotone in the sense of Milgrom (1981), it is easy to see that the optimal decision for the firm is to undertake the project if the signal is above a threshold $\underline{\sigma}$.

For illustration purposes, we now entertain a specific information structure that makes this point clear and it is known as true-noise. With probability $\lambda$ the signal coincides with the value of the project, $\sigma=\theta$. With probability $1-\lambda$ the signal is completely uninformative. That is, it is distributed according to $G(\sigma)$. Given this information structure, the decision to acquire information can be written as

$$
\max _{\underline{\sigma}} \int_{\underline{\sigma}}^{1}\left[\lambda(\beta \sigma-c)+(1-\lambda) \int_{0}^{1}(\beta \theta-c) g(\theta) d \theta\right] g(\sigma) d \sigma-k \geq \int_{0}^{1}(\beta \theta-c) g(\theta) d \theta .
$$

The optimal threshold for the signal to carry out the project is now

$$
\underline{\sigma}^{*}=\underline{\theta}^{*}-\frac{1-\lambda}{\lambda \beta} \int_{0}^{1}(\beta \theta-c) g(\theta) d \theta
$$

where $\underline{\theta}^{*}=\frac{c}{\beta}$ is the threshold in the perfect information case. As a result, we have that $\underline{\sigma}^{*} \leq \underline{\theta}^{*}$ and $\underline{\sigma}^{*}$ is increasing in $\lambda$. The intuition is as follows. When the firm receives a signal below $\underline{\theta}^{*}$ with probability $\lambda$ it implies a loss. However, with probability $1-\lambda$ the signal is noise and the project has an average profitability that we have assumed to be positive. Therefore, the firm is willing to undertake the project if the loss is sufficiently small or the signal is not sufficiently accurate. This intuition explains why the threshold is below the perfect information one and increasing in $\lambda$. 
Following the arguments in the main text, the firm will acquire information if $k<$ $K(\beta, \lambda)$ where

$$
K(\beta, \lambda)=\int_{\underline{\sigma}^{*}}^{1}\left[\lambda(\beta \sigma-c)+(1-\lambda) \int_{0}^{1}(\beta \theta-c) g(\theta) d \theta\right] g(\sigma) d \sigma-\int_{0}^{1}(\beta \theta-c) g(\theta) d \theta .
$$

This threshold is increasing in $\lambda$. That is,

$$
\begin{aligned}
\frac{\partial K}{\partial \lambda} & =\int_{\underline{\sigma}^{*}}^{1}(\beta \theta-c) g(\theta) d \theta-\left(1-G\left(\underline{\sigma}^{*}\right)\right) \int_{0}^{1}(\beta \theta-c) g(\theta) d \theta \\
& =G\left(\underline{\sigma}^{*}\right) \int_{\underline{\sigma}^{*}}^{1}(\beta \theta-c) g(\theta) d \theta-\left(1-G\left(\underline{\sigma}^{*}\right)\right) \int_{0}^{\underline{\sigma}^{*}}(\beta \theta-c) g(\theta) d \theta>0 .
\end{aligned}
$$

That is, the more accurate is the signal the more willing is the firm to acquire information.

The rest of the analysis of the paper follows under this more general structure. The only difference is that the characterization of thresholds will now be based on the signal and the distortion discussed here towards the selection of worse projects will appear.

\subsection{Upfront Payments}

The benchmark model implicitly assumes that the firm only pays for the construction costs and the acquisition of information and receives a stream of revenues related to the usage of the infrastructure. A more general approach would consider that the firm could make additional payments to the government in exchange for a larger share of the revenues from the concession. It is clear that these additional payments would mitigate the incentive problem that lies behind the distortions uncovered in this paper. In particular, if the firm could contribute additional funds up to $d$, the optimal selection of projects could always be achieved with $\beta=1$ since this would be akin to the principal selling the concession to the firm. As we will see in this section, however, such an strategy is often suboptimal since it would lead to excessive rents for the firm.

While the previous situation is theoretically possible, in practice it is very unlikely that a firm can pay upfront for all the externalities that the infrastructure generates. A more plausible assumption is that the firm has access to funds $m$ enough to finance the 
infrastructure and the cost of acquiring information but not sufficient to cover the social value $d$. That is, $m \in[c+k, c+k+d)$. The next proposition shows that, when the first best cannot be attained otherwise, it is optimal to use all the additional funds as an upfront payment to mitigate the incentive problem.

Proposition 5. Assume $m \in[c+k, c+k+d)$ so that the firm can make upfront payments, $f \in[0, m-(c+k)]$. Define

$$
K(\beta, m-k) \equiv-\int_{0}^{\frac{m-k}{\beta}}(\beta \theta-(m-k)) g(\theta) d \theta .
$$

Then, the optimal concession contract can be characterized as follows

1. If $k \leq \hat{K}=\frac{K\left(\frac{c}{c+d}, c\right)}{c+K\left(\frac{c}{c+d}, c\right)} m$, the first best can be attained. The optimal contract corresponds to an upfront payment

$$
f^{*}(k)= \begin{cases}0 & \text { if } k \leq K\left(\frac{c}{c+d}, c\right), \\ c\left[\frac{k}{K\left(\frac{c}{c+d}, c\right)}-1\right] & \text { otherwise }\end{cases}
$$

and $\beta^{*}=\frac{c+f^{*}(k)}{c+d}$.

2. If $k \in(\hat{K}, \tilde{K}]$, then the optimal contract is characterized by an upfront payment $f^{*}=m-(c+k)$ and a value $\beta^{*}(k)$ implicitly defined by $K\left(\beta^{*}, m-k\right)=k$.

3. If $k>\tilde{K}$ the optimal allocation can be implemented with any $f \in[0, m-(c+k)]$ with $\beta^{*}=\frac{c+f}{E(\theta)}$.

The threshold $\tilde{K}$ is defined as $E_{I}(\tilde{K})+\tilde{K}=E_{I I}$ where

$$
E_{I}(k)=\int_{c+d}^{\frac{m-k}{\beta^{*}(k)}}(\theta-(c+d)) g(\theta) d \theta .
$$

and $E_{I I}$ is defined in (3).

The previous proposition illustrates several facts. The first one is that upfront payments, when feasible, are used in equilibrium. However, the optimal upfront payment 
often is not maximal. The reason is that a larger upfront payment is associated with a larger $\beta$ which translates into higher rents when $\theta$ is high. In other words, in order to keep $\underline{\theta}^{*}$ constant when $f$ increases the principal needs to award a larger proportion of the rents of the project $\beta$ to the contractor. This change, by making the profits more responsive to the realization of $\theta$, fosters the acquisition of information by the firm in order to avoid the losses when $\theta$ is low. This same responsiveness makes the profits much larger when $\theta$ is high, increasing expected firm rents. As a result, the use of upfront payments would only be optimal if $k$ is high enough so that the efficient selection of projects cannot be attained otherwise.

This proposition also shows that when in the benchmark case the first best can be attained, upfront payments are not optimal because, due to the previous argument, they transfer rents to the firm. For higher values of $k$, it is optimal to set the minimal upfront payment to allow the principal to achieve the first best. When this is not possible, however, upfront payments are set to the maximum and, as in the benchmark model, $\beta$ is distorted to generate incentives for information acquisition. Also as in that case, if $k$ is very high providing incentives is too costly and upfront payments become irrelevant.

As it can also be observed from the proposition, an increase in $m$ raises $\hat{K}$, making the first best attainable for larger values of $k$. In the intermediate region, more projects are carried out, reducing type-I errors ${ }^{16}$ Because the type-II error is independent of $m$, $\tilde{K}$ is also increasing in $m$. Hence, information acquisition occurs for a larger range of costs of information.

Overall, allowing for upfront payments does not change qualitatively the results of the paper but, as the next result summarizes, it leads to better project selection and higher

\footnotetext{
${ }^{16}$ In particular, the worst project that the firm undertakes satisfies the condition
}

$$
k=-\int_{0}^{\underline{\theta}^{*}}(m-k)\left(\frac{\theta}{\underline{\theta}^{*}}-1\right) g(\theta) d \theta,
$$

so that $\underline{\theta}^{*}$ is decreasing in $m$. 
social welfare. This result is summarized in the following corollary.

Corollary 2. When $m$ increases,

1. Social welfare increases,

2. White elephants are less likely, and

3. Equilibrium decision errors are smaller.

\subsection{Distortions and Externalities}

In the benchmark model we have interpreted $\beta$ as the duration of the concession contract. That is, during a proportion $\beta$ of the future, the firm could reap all the returns from the project.

This simple setup has two main limitations. First, market power typically generates a loss to society that the firm cannot appropriate. Second, a concession contract comprises many terms like the price and the duration, many combinations of which lead to the same $\beta$ but have different welfare implications.

A demand model that would be consistent with our assumptions would be such that $D(p)=1$ if the price $p \leq \theta$ and $D(p)=0$ otherwise. Obviously, in this case no distortion would arise and, contingent on production, surplus would always equal $\theta$. Furthermore, any combination of a duration of the concession, denoted as $\gamma$, and price, $p$, such that $\gamma p$ is constant would be equivalent.

In more general contexts the two previous limitations might become relevant. We will not discuss here the trade-off between the price and the duration of the concession as this is an issue that has been studied at length in the literature, for example in the context of patent design ${ }^{17}$ Instead, we focus on the effects of introducing static distortions.

\footnotetext{
${ }^{17}$ Two classical references of the conditions necessary for one dimension to be less distortionary than the other are provided by Klemperer (1990) and Gilbert and Shapiro (1990).
} 
Suppose that a price $p>0$ leads to profits $\theta$ for the firm and a distortion $\delta$ while this concession is in place. Assume also that absent a concession (when $p=0$ ) consumer surplus implies that $\theta$ generates a total surplus $s \theta$ with $s \geq 1$. Total welfare can, thus, be written as

$$
W=\beta(1-\delta) s \theta+(1-\beta) s \theta=(1-\beta \delta) s \theta \equiv \Delta \theta,
$$

where, $(1-\delta) s \geq 1$ implies $\Delta \geq 1$. As in the benchmark model, the firm would have excessive incentives to invest if $\Delta \leq \frac{c+d}{c}$ and, hence, $\beta^{*} \leq 1$ when $k=0$. In that case, when $k>0$ similar effect to the ones discussed in earlier sections would emerge here.

\subsection{Ex-ante Unprofitable Investments}

A maintained assumption throughout the paper was that $E(\theta) \geq c+d$, meaning that without information the project had a net positive expected value. The acquisition of information was useful to screen out bad projects that without it would be undertaken.

It is reasonable to believe that the previous assumption captures the natural default case. The reason is that the project under consideration is likely to be the outcome of a wider selection process in which alternatives with lower expected value had already been weeded out.

Nevertheless, we now discuss how the results change if $E(\theta)<c+d$. From a social standpoint, in this case the project should be undertaken if and only if information has been acquired and $\theta \geq c+d$. As a result, the acquisition of information is socially valuable if $k \leq K^{s} \equiv \int_{c+d}^{1}[\theta-(c+d)] g(\theta) d \theta$.

As in the benchmark model, under a concession contract, choosing a $\beta^{*}=\frac{c}{c+d}$ implements the first best when $k$ is small. For $k$ sufficiently large there is no distortion either, since the project is never carried out. For intermediate values of $k$, however, as in the case discussed in the main text, the firm lacks incentives to acquire information. As shown in Figure 1, when $\theta \geq \underline{\theta}^{s}$ the private returns when $\beta^{*}=\frac{c}{c+d}$ are smaller than the 
social returns. As a result we have two situations. When $k$ is relatively small, $\beta$ must be distorted upwards as this increases the rents for the firm when it acquires information and carries out the project. Notice that this higher $\beta$ leads to undertaking projects that are not socially efficient since $\underline{\theta}^{*}<\underline{\theta}^{s}$. When $k$ is relatively large, the high $\beta$ necessary implies that many bad projects would be undertaken and it is socially preferable to not acquire information and not carry out any project.

One implication of this discussion is that the firm never incurs in losses in the equilibrium path. Either the project will not be undertaken or only those that have a private positive return will be carried out. Thus, limits on the losses or the anticipation of the renegotiation of the concession play no role and have no effect on the incentives to acquire information.

Finally, the characterization of the flexible-term contract that attains the first best here is simple. The function $\beta(\theta)$ must satisfy three conditions. When $\theta<\underline{\theta}^{s}$ then $\beta(\theta)=0$ in order not to undertake inefficient projects. When $\theta \geq \underline{\theta}^{s}$ and $k \leq K^{s}$ it has to satisfy the condition

$$
\int_{c+d}^{1}[\beta(\theta) \theta-c] g(\theta) d \theta=k
$$

so that the firm has incentives to acquire information. Finally, when $\theta \geq \underline{\theta}^{s}, \beta(\theta) \geq \frac{c}{\theta}$ so that undertaking good projects is profitable. Of course, the optimal contract is not uniquely defined. Also, notice that this contract is simpler than the one in the main text which required payments for not carrying out the project. There is an intuitive reason for that. The idea of flexible-term contracts is to reward the firm when the project is worthwhile. In the baseline model, this reward makes the ex-ante problem of acquiring information worse. In current case, however, rewarding the firm when $\theta$ is high provides more incentives to acquire information in order to undertake good projects. 


\subsection{Competition}

Our benchmark model assumes that only one firm can carry out the project. However, most concessions are awarded competitively through an auction. To address this issue, in this section we discuss a simple model of competition that emphasizes an additional force that operates in the same direction and complements the results discussed in our benchmark framework.

Consider the case of two identical firms $i=1,2$ bidding to build the same project. The project is allocated according to a second-price auction. Each firm bids $\beta_{i}$. The firm that offers the lowest $\beta$ wins the auction and the price, denoted as $\beta^{c}$, is set according to the losing bid. As in the previous sections this price can be interpreted as the proportion of the value of the project that is allocated to the contractor, for example, through the combination of a toll level and a duration of the concession contract. Hence, the firm that commits to receive the lowest proportion of the value of the project wins.

In the benchmark model the principal sets $\beta$ optimally. An important difference here is that $\beta$ is now determined in equilibrium and not directly as part of the contract. However, as it is typically the case in auction design, the principal can still affect the resulting $\beta$ by setting a reserve price. In particular, we denote the price ceiling below which the bid will be accepted and the concession awarded to the winning firm as $\bar{\beta}$.

Similarly to what we assumed in the benchmark model, here we suppose that firms decide to get informed or not before placing a bid and after knowing the reserve price in the auction. To keep things simple, we also assume that, although the result of this investment is private information, whether a firm gets informed or not is observable but not contractible before placing the bid.

The timing of the model is now as follows. In the first stage, the government sets the reserve price. Second, firms decide simultaneously whether to pay $k$ to get informed or 
not. Finally, firms decide simultaneously on $\beta_{i}$, for $i=1,2$.

Solving the model by backward induction, we start by analyzing the bidding behavior of firms in the last stage as a function of their information investment decisions. As it is standard, we focus on the weakly dominant strategy equilibrium of the second-price auction. In our framework this means that firm $i$ bids to receive a share of the value of the project $\beta_{i}$ so that it breaks even given the available information. Of course, if this break-even $\beta_{i}$ is higher than $\bar{\beta}$ firm $i$ will not participate in the auction.

There are three cases to be analyzed. First, both firms get informed. Then, each firm learns the real $\theta$ and bids $\beta_{i}=\frac{c}{\theta}$. As a result, their profits are equal to $-k$. Second, none of the firms gets informed. In that case, firms bid according to their expected value, $\beta_{i}=c / E(\theta)$ as long as $\bar{\beta}>c / E(\theta)$ and they do not participate otherwise. In either case, firms make expected profits of 0 . Finally, if one firm gets informed, say firm 1, firm 2 does not participate due to the Winner's Course. As firm 1 knows the profitability of the project and bids a break-even $\beta_{1}=c / \theta$, firm 2 faces two outcomes. Either it loses the auction and gets 0 or it wins and in that case, it loses money. Thus, it is a weakly dominant strategy not to participate and, consequently, the equilibrium price is given by the reserve price $\bar{\beta}$. In this case we can compute expected profits for firm 1 when it gets informed as

$$
\pi^{c}(\bar{\beta})=\int_{\frac{c}{\beta}}^{1}(\bar{\beta} \theta-c) g(\theta) d \theta-k .
$$

With the previous payoffs, we can now move to the second stage of the game in which firms decide whether to get informed or not. In the next payoff matrix we represent the profits of both firms as a result of their investment decision. 
Firm 2

\begin{tabular}{|c|c|c|}
\hline & Investment & No Investment \\
\hline Investment & $-k,-k$ & $\pi^{c}(\bar{\beta}), 0$ \\
\hline No Investment & $0, \pi^{c}(\bar{\beta})$ & 0,0 \\
\hline
\end{tabular}

Notice that if $k$ is sufficiently large $\pi^{c}(\bar{\beta}) \leq 0$ and the only equilibrium corresponds to neither firm getting informed. Otherwise, if $\pi^{c}(\bar{\beta})>0$, the payoffs resemble those of a Chicken Game. This game has two asymmetric equilibria in pure strategies and one symmetric mixed-strategy equilibria. We will focus on the latter, in which firms randomize between getting informed (with probability $\alpha_{i}$ ) and not doing so. This equilibrium can be easily characterized by equating the payoff of acquiring information with those that arise when the firm does not get informed, 0 . In the symmetric equilibrium $\alpha_{i}=\alpha^{*}$ for $i=1,2$ and this probability is equal to

$$
\left(1-\alpha^{*}\right) \int_{\frac{c}{\beta}}^{1}(\bar{\beta} \theta-c) g(\theta) d \theta-k=0 .
$$

In the first stage the principal sets the reserve price, $\bar{\beta}$, to maximize social welfare. Notice that this reserve price only affects the probability that firms get informed. From equation (7), we can observe that increases in $\bar{\beta}$ raise $\alpha^{*}$. This is an important difference with respect to our benchmark model. In that case, changes in $\beta$ affected the rents that firms obtained when they decided not to get informed. Here these rents are always 0 by virtue of competition.

We can write down the maximization problem of the principal as

$$
\begin{gathered}
\max _{\bar{\beta}} \int_{\frac{c}{\beta}}^{1}(\theta-(c+d)) g(\theta) d \theta+\left(1-\alpha^{*}\right)^{2} \int_{0}^{\frac{c}{\beta}}(\theta-(c+d)) g(\theta) d \theta-2 \alpha^{*} k, \\
\text { s.t. }\left(1-\alpha^{*}\right) \int_{\frac{c}{\beta}}^{1}(\bar{\beta} \theta-c) g(\theta) d \theta-k=0 .
\end{gathered}
$$

The first term refers to the surplus of the projects that generate non-negative profits for a firm when it is informed. Those projects are always undertaken regardless of whether 

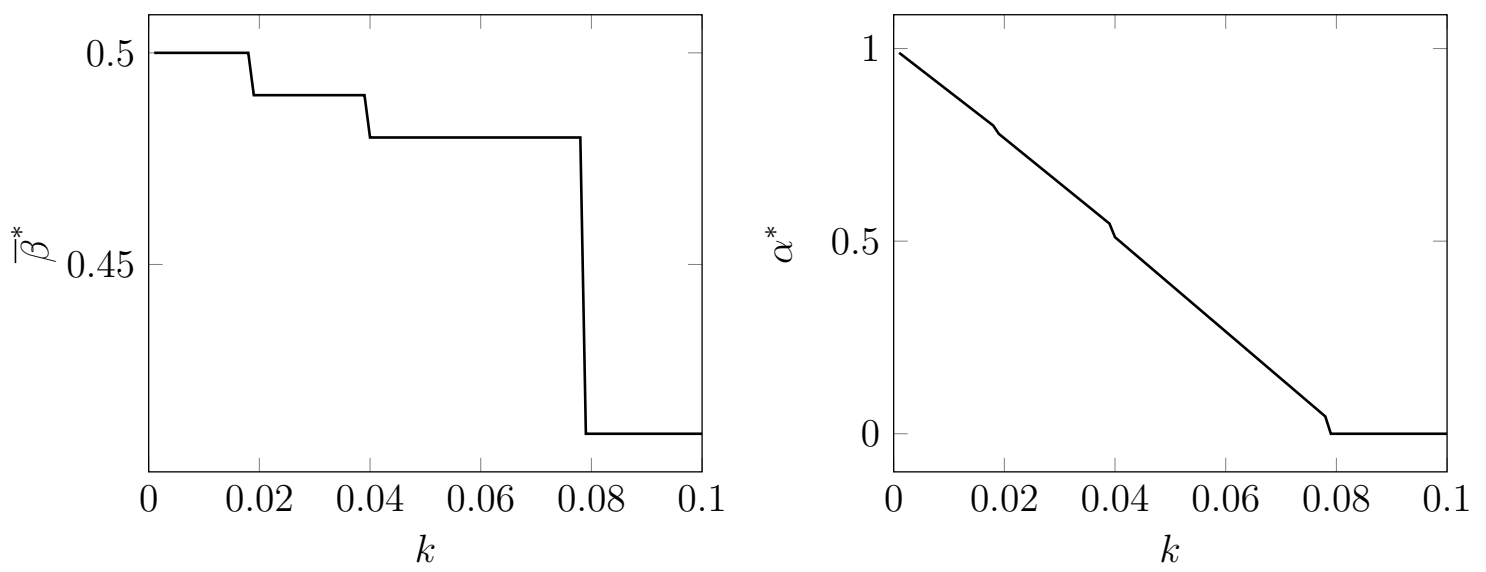

Figure 4: Optimal reservation price and probability that the each firm acquires information as a function of $k$. The remaining parameters are $c=d=0.2$ and $\theta \sim U[0,1]$.

any firm is informed or not. The second term refers to the projects that informed firms would not carry out given the reserve price. Those projects are undertaken when both firms are uninformed, which happens with probability $\left(1-\alpha^{*}\right)^{2}$. The third term captures the total expected costs of firms getting informed.

This maximization has no explicit solution and for this reason we rely on the simulation in Figure 4 to convey the intuition for the results. When $k=0$ firms always get informed and $\alpha^{*}=1$. In that case, it is socially optimal to choose $\bar{\beta}=\frac{c}{c+d}$ as this guarantees that all efficient projects and only those are carried out.

In the benchmark model, when the costs of learning increase the principal must decrease $\bar{\beta}$ in order to provide incentives for firms to get informed. As noticed before, the reason for the negative relationship between $k$ and $\bar{\beta}$ is different here. Competition leads to excessive incentives for firms to get informed. This is the result of a standard externality: firms acquire information without taking into account that by doing so they reduce the value of the information that their competitor is also acquiring. As $k$ becomes sufficiently large, it eventually becomes optimal to induce no learning. This is achieved through $\bar{\beta} \geq \frac{c}{E(\theta)}$. In that case, competition among firms will dissipate all the profits.

The benchmark model and the competition setup studied here constitute two extreme 
cases in which increases in the cost of acquiring information lead to a decrease in the share of the project being assigned to the contractor, although for very different reasons. In a more general case, several heterogeneous firms might participate in the auction - for example, with different $\operatorname{costs} c_{i}-$, leading to an intermediate level of competition. Our results for the extreme cases make intuitive the prediction that both effects operating in the same direction would emerge in combination in this situation, although each of them in a weaker version.

Another aspect to be considered in this model of competition is the risk of tacit collusion. If both firms collude they will offer $\beta=\bar{\beta}$. If the principal anticipated this collusion the optimal price ceiling would coincide with the optimal $\beta$ analyzed in the benchmark model. Notice that even in that case, this policy would not eliminate the incentives to collude because, for sufficiently low values of $k$, the contractor makes positive profits.

\section{Concluding Remarks}

This paper emphasizes the effects of considering the selection of projects in the characterization of the optimal concession contract. The renegotiation that has been a focus in the literature is often the reflection of an underlying poor project selection. The main insight of our analysis is that when this is the case it is optimal to transfer part of the demand risk to the contractor in order to foster the acquisition and better use of information. Institutional frameworks that limit the losses that the firm can absorb aggravate this incentive problem. Hence, an important lesson from our analysis is that in case of failure the firm and its debtors should only be compensated for the present value of the concession from that point on. The incentives to acquire information on the profitability of the project by the contractor will depend on the commitment power of the principal to such a policy. 
Our model abstracts from several important aspects. In particular, our principalagent model assumes that the project is given. Many times, however, the project is proposed by the firms that might carry it out. This introduces an additional reason why demand is endogenous to the firm's actions. Allowing for the project to be strategically offered requires the optimal mechanism to have a screening component. When this component is not considered additional distortions might arise. An illustration of that is the Castor Project, the biggest investment in the natural gas system in Spain, consisting of a submarine gas storage facility by the east coast. This project, aimed to store up to 1.3 billion cubic meters of gas, was sponsored by a firm specialized in this kind of infrastructure. Amid the concerns about the risk of generating earthquakes due to the location of the storage facility close to a tectonic fault, the sponsor/concessionary was protected from this contingency by the contract in spite of its information advantage over the administration. The earthquakes materialized soon after the project had started and the Spanish government was forced to suspend the works and compensate the firm.

Finally, although we introduce a simple model of competition and a procurement auction our approach makes several restrictive assumptions such as a second price mechanism or the fact that the acquisition of information is known to all firms. A more general approach to competition would require the optimal mechanism to not only generate incentives for firms to acquire information but also to aggregate it in a way that minimizes the winner's course.

\section{References}

Bain, Robert and Lidia Polakovic, "Traffic Forecasting Risk Study Update 2005: Through Ramp-Up and Beyond," Technical report, Standard and Poors, 2005.

Bullen, Ross, "This Alarming Generosity": White Elephants and the Logic of the Gift," American Literature, December 2011, 83(4), pp. 747-773. 
Demski, Js And DAVID SAPpington, "Delegated Expertise," Journal of Accounting Research, 1987, 25(1), pp. 68-89.

Engel, Eduardo, Ronald Fischer and Alexander Galetovic, "Highway Franchising: Pitfalls and Opportunities," American Economic Review, May 1997, 87(2), pp. $68-72$.

Engel, Eduardo, Ronald Fischer, Alexander Galetovic and Ginés De Rus, "Colaboración Público-Privada en infraestructuras: Reforma del sistema concesional español de autopistas de peaje," Policy Papers 2015-11, FEDEA, November 2015.

Engel, Eduardo, Ronald D. Fischer and Alexander Galetovic, The Economics of Public-Private Partnerships, number 9781107035911 in Cambridge Books, Cambridge University Press, 2014.

Engel, Eduardo M. R. A., Ronald D. Fischer and Alexander Galetovic, "Least-Present-Value-of-Revenue Auctions and Highway Franchising," Journal of Political Economy, October 2001, 109(5), pp. 993-1020.

Feess, Eberhard And Markus WalzL, "Delegated expertise-when are good projects bad news?" Economics Letters, 2004, 82(1), pp. 77-82.

Flyvbjerg, Bent, Mette K. Skamris Holm and Søren L. Buhl, "How Common and How Large Are Cost Overruns in Transport Infrastructure Projects?" Transport Reviews, 2003, 23(1), pp. 71-88.

—, "How (In)accurate Are Demand Forecasts in Public Works Projects?: The Case of Transportation," Journal of the American Planning Association, 2005, 71(2), pp. 131146.

Gilbert, Richard And Carl Shapiro, "Optimal Patent Length and Breadth," RAND Journal of Economics, Spring 1990, 21(1), pp. 106-112.

Guasch, J. Luis, Granting and Renegotiating Infrastructure Concessions : Doing it Right, number 15024 in World Bank Publications, The World Bank, 2004.

Klemperer, Paul, "How Broad Should the Scope of Patent Protection Be?" RAND Journal of Economics, Spring 1990, 21(1), pp. 113-130. 
LAMBERT, RichARD, "Executive effort and selection of risky projects," RAND Journal of Economics, 1986, 17.

Milgrom, Paul R., "Good News and Bad News: Representation Theorems and Applications," Bell Journal of Economics, Autumn 1981, 12(2), pp. 380-391.

Nordhaus, William, Invention, Growth, and Welfare, MIT Press, Massachussets, 1969.

Persico, Nicola, "Information Acquisition in Auctions," Econometrica, 2000, 68(1), pp. $135-148$.

Robinson, James A. And Ragnar Torvik, "White Elephants," Journal of Public Economics, 2005, 89, pp. 197-210.

Szalay, Dezsö, "Contracts with Endogenous Information," Games and Economic Behavior, 2009, 65(2), pp. 586-625.

Weyl, E. Glen and Jean Tirole, "Market Power Screens Willingness-to-Pay," The Quarterly Journal of Economics, 2012, 127(4), pp. 1971-2003.

Zambrano, Andrés, "Motivating Informed Decisions," Economic Theory, 2019, 67, pp. 645-664.

\section{A Proofs}

Proof of Lemma 1; From the text we know that the first best requires to acquire information if $k \leq K^{s}$ and in that case to carry out projects if $\theta \geq c+d$. As we have seen in the text the firm carries out these projects if $\beta=\frac{c}{c+d}$. Notice that

$K\left(\frac{c}{c+d}\right)=-\int_{0}^{c+d}\left[\frac{c \theta}{c+d}-c\right] g(\theta) d \theta=-c \frac{c}{c+d} \int_{0}^{c+d}[\theta-(c+d)] g(\theta) d \theta=\frac{c}{c+d} K^{s}$.

Hence, the first best is achieved if $k \leq K\left(\frac{c}{c+d}\right)$ and $\beta=\frac{c}{c+d}$. When $k \in\left(K\left(\frac{c}{c+d}\right), K^{s}\right)$ an inefficiency arises since providing the incentives to do the right projects does not induce the firm to acquire information.

Finally, if $K>K^{s}$ it is not efficient to acquire information in the first place but the project should be carried out. This can be achieved with $\beta \geq \frac{c}{E(\theta)}$. 
Proof of Proposition 1: The optimum when $k<K\left(\frac{c}{c+d}\right)$ or $k>K^{s}$ is immediate from the proof of Lemma 1. In the remaining region, when $k \in\left(K\left(\frac{c}{c+d}\right), K^{s}\right)$ the total surplus in the first best corresponds to

$$
W^{s}(k)=\int_{c+d}^{1}[\theta-(c+d)] g(\theta) d \theta-k .
$$

As explained in the text, when we set $\beta=K^{-1}(k)$ the firm has incentives to acquire information. The welfare achieved in this case is

$$
W^{s}(k)-E_{I}(k) .
$$

When no information is acquired all projects are carried out if $\beta=\frac{c}{E(\theta)}$ and welfare corresponds to

$$
W^{s}(k)-E_{I I}+k \text {. }
$$

As a result, the firm should acquire information if and only if

$$
E_{I}(k) \leq E_{I I}-k
$$

As $E_{I}(k)$ is increasing in $k$ there will be a unique cutoff point $\tilde{K}$ such that information is acquired if and only if $k \leq \tilde{K}$.

Proof of Proposition 2: Immediate from the proof of Proposition 1.

Proof of Proposition 3: In order to show that the contract is optimal we need to show that four conditions are satisfied:

$$
\begin{aligned}
\rho_{P}(k)(1-G(c+d))+\rho_{N}(k) G(c+d)-k & \geq 0, \\
\rho_{P}(k) \geq \rho_{N}(k) & \geq 0, \\
\rho_{P}(k)(1-G(c+d))+\rho_{N}(k) G(c+d)-k & \geq \rho_{N}(k), \\
\rho_{P}(k)(1-G(c+d))+\rho_{N}(k) G(c+d)-k & \geq \rho_{P}(k)(1-G(c+d))-c G(c+d) .
\end{aligned}
$$

Equation $(\overrightarrow{\mathrm{PC}})$ is the participation constraint. Condition $\mathrm{IC} 0$ guarantees that if the firm acquires information it carries out all projects if and only if $\theta \geq c+d$. Conditions (IC1) and (IC2) guarantee that the firm does not prefer to not acquire information and not carrying out all projects or carrying out all of them, respectively.

Condition (IC2) means that $\rho_{N}(k) \geq \frac{k}{G(c+d)}-c$. Notice also that the first part of condition (IC0) is satisfied if (IC1) holds. Thus, when $k \leq c G(c+d)$ we can implement the 
first best with $\rho_{N}(k)=0$ since this also satisfies $(\mathrm{PC})$ and $(\mathrm{IC1})$ when $\rho_{P}(k)=\frac{k}{1-G(c+d)}$ and the firm receives no rents.

When $k \geq c G(c+d), \rho_{N}(k)=\frac{k}{G(c+d)}-c \geq 0$ and from (IC1) we have that (PC) is not binding. In order to minimize rents we need (IC1) to hold with equality which implies

$$
\rho_{P}(k)=\rho_{N}(k)+\frac{k}{1-G(c+d)},
$$

proving the result.

Proof of Proposition 4: From Proposition 3 we know that if $k \leq c G(c+d)$ the first best can be implemented with $\rho_{N}(k)=0$. This means, following the proof of the previous proposition, that the conditions that need to be guaranteed in the optimal contract with information acquisition are

$$
\begin{aligned}
\rho_{P}(k)(1-G(\underline{\theta}))-k & \geq 0, \\
\rho_{P}(k) & \geq 0, \\
\rho_{P}(k)(1-G(\underline{\theta}))-k & \geq \rho_{P}(k)(1-G(\underline{\theta}))-c G(\underline{\theta}) .
\end{aligned}
$$

Hence, for condition (IC2) to hold and minimize the distortions we need that $k=$ $c G\left(\underline{\theta}^{f t}\right)$. Furthermore, from (PC) rents are minimized if $\rho_{P}(k)=\frac{k}{1-G\left(\underline{\theta}^{f t}\right)}$.

The rest of the contract can be characterized as in the benchmark model.

Proof of Proposition 5: We start by noticing that given an upfront payment $f \geq 0$ a firm will decide to acquire information if

$$
\max _{\underline{\theta}} \int_{\underline{\theta}}^{1}(\beta \theta-c-f) g(\theta) d \theta-k \geq \int_{0}^{1}(\beta \theta-c-f) g(\theta) d \theta .
$$

This means that if the firm acquires information only projects with $\theta \geq \underline{\theta}=\frac{c+f}{\beta}$ will be carried out. Information will be acquired if

$$
k \leq K(\beta, c+f) \equiv-\int_{0}^{\frac{c+f}{\beta}}(\beta \theta-c-f) g(\theta) d \theta .
$$

This expression increases in $f$ meaning that maximizing the incentives for firms to acquire information requires $f=m-c-k$, which leads to (6).

Regarding part 1 , if $\beta=\frac{c+f}{c+d}$ the first-best project selection can always be achieved and $\underline{\theta}^{s}=c+d$. Profits for the contractor when this optimal $\beta$ is used can be computed as

$$
\Pi(f)=(c+f) \int_{c+d}^{1}\left(\frac{\theta}{c+d}-1\right) g(\theta) d \theta-k
$$


which is increasing in $f$. Since the government aims to minimize firm rents subject to the efficient allocation, the optimal contract the minimum $f$ should be used. Proposition 1 indicates that when $k \leq K\left(\frac{c}{c+d}, c\right)$ the first best does not require upfront payments.

For $k>K\left(\frac{c}{c+d}, c\right)$, the benefit of getting informed, measured as $K\left(\frac{c+f}{c+d}, c+f\right)$ is increasing in $f$. Hence, in order to minimize rents, the optimal $f$ is the minimum value for which the firm prefers to get informed, $k=K\left(\frac{c+f}{c+d}, c+f\right)$. Solving for $f$ yields the expression $f^{*}(k)=c\left[\frac{k}{K\left(\frac{c}{c+d}, c\right)}-1\right]$. As a result, the optimal selection of projects can be attained when the available funds are higher than the necessary upfront payment, $f^{*}(k) \leq m-(c+k)$. Given $m$ there is a value $\hat{K}$ so that if $k \leq \hat{K}$ the optimal selection is possible.

For $k>\hat{K}$ the first-best cannot be attained with funds $m$. In that case, some projects that are socially worthwhile will not be carried out. The threshold value for $k$ can be rewritten in terms of the marginal project $\underline{\theta}=\frac{c+f}{\beta}$ as $K\left(\frac{c+f}{\underline{\theta}^{*}}, c+f\right)$ which is increasing in $f$ and $\underline{\theta}^{*}$. Hence, the set of projects carried out will be maximized if $f=m-(c+k)$. For a given $k$ the optimal $\beta$ is characterized by $K(\beta, m-k)=k$.

If the firm does not get informed, profits become $\int_{0}^{1}(\beta \theta-(c+f)) g(\theta) \theta$. Any combination $(\beta, f)$ such that $\beta=\frac{c+f}{E(\theta)}$ yields the same total welfare since it reduces firm profits to 0 .

Along the lines of Proposition 1, the threshold value for which it is not worthwhile to induce learning can be characterized by comparing welfare in both situations. 